\title{
Biopolítica nas Ruas: a Produção de Modos de Vida Seguros
}

\author{
Biopolitics on The Streets: the Production of Safe Ways of Living \\ Biopolitica en Las Calles: la Producción de Modos de Vida Seguros
}

\section{Wanderson Vilton Nunes da Silva}

Doutorando (CAPES) em Psicologia Social e Institucional na Universidade Federal do Rio Grande do Sul. Formado em Psicologia pela Universidade Federal de Alagoas (2011) e Mestrado em Psicologia pela mesma Instituição (2013). Suas temáticas de interesse são as seguintes: políticas públicas, direitos humanos, o urbano e a cidade, população de rua, processos de subjetivação e formação em psicologia.

E-mail: wandersonvilton@gmail.com

\section{Simone Maria Hüning}

Professora Adjunta III do Curso de Psicologia e docente pesquisadora do Mestrado em Psicologia da Universidade Federal de Alagoas. Possui graduação em Psicologia pela Universidade de Santa Cruz do Sul (2000), mestrado e doutorado em Psicologia pela Pontifícia Universidade Católica do Rio Grande do Sul. Seus principais temas de interesse são os estudos foucaultianos, processos de subjetivação, cultura, governamentalidade, produção de conhecimento, ética e pesquisa em psicologia. É líder do grupo de pesquisa "Processos Culturais, Políticas e Modos de Subjetivação".

E-mail: simonehuning@yahoo.com.br

\section{Resumo}

Este artigo busca problematizar a produção de homicídios de moradores de rua em Maceió, bem como as estratégias de governo de conduta elaboradas a partir dos assassinatos daqueles sujeitos, desde julho de 2010. Para isto, primeiramente abordamos informações de textos midiáticos produzidos entre julho de 2010 e setembro de 2012, além de relatório do Ministério Público Estadual sobre estes assassinatos, nos quais problematizamos a morte como espetáculo midiático, desafio e resultado de uma racionalidade biopolítica. Em seguida, abordamos documentos elaborados pelo Comitê Intersetorial criado em resposta a estes assassinatos, no que se refere à lógica de garantia de direitos e à elaboração de estratégias de enfrentamento para estes problemas. Por fim, ressaltamos o aspecto produtivo do poder, tendo na vida dos viventes seu objeto de intervenção privilegiado, além de ressaltarmos as possibilidades de resistência inerentes a estes processos que possibilitam a reinvenção da vida e dos mecanismos de poder.

Palavras-chave: Moradores de rua; Biopoder; Governo; Produção de mortalidade; Políticas sociais. 


\begin{abstract}
This article seeks to bring into question the recent production of murders of homeless people in Maceio, as well as the government's conduct strategies drawn from these murders, since July 2010. For this, first we approach the information found both in the media texts produced between July 2010 and September 2012, and the report from the local Department of Public Prosecution about these homicides. In them, death can be apprehended as a media spectacle, challenge and the result of a biopolitical rationality. After that, we approach the documents prepared by the Intersectoral Committee, created in response to these killings. Such documents shed light on the logic of ensuring rights and the development of coping strategies for these problems. Finally, this paper emphasizes on how power is actually produced, having the lives of the living as its privileged object of intervention. Furthermore, we underline the possibilities of resistance inherent in these processes, which enable the reinvention of life and the mechanisms of power.
\end{abstract} Keywords: Homeless people; Biopower; Government; Production of mortality; Social Policies.

\title{
Resumen
}

Este artículo trata de problematizar la producción de homicidios de habitantes de calle en Maceió y también las estrategias de gobierno de las conductas elaboradas con las denuncias de estos asesinatos, desde julio de 2010. Para ello, primero fueron utilizados textos de periódicos elaborados entre julio de 2010 y septiembre de 2012, sobre estos asesinatos, en los cuales cuestionamos tales muertes cuando concebidas como un espectáculo mediático, comprendiéndolas como desafío y resultado de una racionalidad biopolítica. Posteriormente abordamos documentos elaborados por el Ministerio Público Estadual y por el Comité Intersectorial creado en respuesta a estos asesinatos, en lo que se refiere a los discursos de garantía de derechos y a la elaboración de estrategias de enfrentamiento para estos problemas. Por fin, resaltase lo aspecto productivo del poder, teniendo en la vida de los vivientes su objeto de intervención privilegiado, también resaltase las posibilidades de resistencia inherentes a estos procesos que posibilitan la reinvención de la vida y de los mecanismos de poder.

Palabras claves: Habitantes de calle; Biopoder; Gobierno; Producción de mortalidad; Políticas sociales. 
Os sites de notícias de Alagoas e do país, a partir de julho de 2010, ocuparam-se em narrar assassinatos de moradores de rua ocorridos em Maceió entre 2010 e 2012. Nesses materiais, os espaços urbanos daquela cidade são descritos como um campo de violência e de morte: entre julho de 2010 e setembro de 2012 foram registrados 88 assassinatos de moradores de rua - numa população estimada em 375 moradores de rua na capital alagoana -, conforme os sites de notícias e a Comissão de Direitos Humanos da Ordem dos Advogados do Brasil em Alagoas $(\mathrm{OAB} / \mathrm{AL})$.

Neste artigo, problematizaremos essas narrativas a partir de dois eixos construídos para abordar estes assassinatos: a produção de mortes (mortalidade) nas cidades e as estratégias de governo para a população de rua na capital de Alagoas.

Sobre a produção de mortes, abordaremos aspectos relacionados à forma como as mortes tornam-se um espetáculo midiático em nossa contemporaneidade e, em seguida, a forma como a morte se torna um desafio para as tecnologias do biopoder. Para isto, consideraremos os textos jornalísticos de sites de notícias publicados entre 2010 e 2012 sobre os assassinatos de moradores de rua em Maceió, além de relatório elaborado pelo Ministério Público Estadual. Quanto às estratégias de governo direcio- nadas à população de rua em Maceió, nos deteremos no documento do Comitê Intersetorial e Inclusivo de Ações e Metas para a População em Situação de Rua para os anos 2011 e 2012, cedido pela Comissão de Direitos Humanos da OAB em Alagoas. A partir deste documento problematizaremos as ações de governo sugeridas para esta população, a lógica de garantia de direitos que atravessam as práticas sugeridas e, por fim, aspectos relacionados à ocupação do tempo e dos espaços numa garantia de controle dos corpos e da circulação destes sujeitos pela cidade.

\section{A morte como um espetáculo midiático e um desafio ao poder}

Nos últimos anos, com os avanços dos meios de comunicação por intermédio da internet, de jornais, dos sites de notícias, as redes de televisão têm se especializado na cobertura ao vivo e in loco de uma série de acontecimentos, entre estes, aqueles relacionados a mortes e assassinatos de pessoas. Tais transmissões garantem um elevado número de telespectadores que assistem em tempo real a um show de cobertura jornalística do assassínio de pessoas. Neste sentido, a morte se torna, entre outras coisas, um produto a ser consumido pelos espectadores, uma imagem em movimento do que 
está acontecendo aqui e agora em algum lugar do mundo. Esta imagem, produto de consumo, movimenta capital e sentimentos, dispara sentidos sobre o viver e sobre o morrer, constitui uma história que vai se agregando à nossa vida, construindo uma história social do que somos.

Se na antiguidade a morte era algo que deveria ser remetido a rituais religiosos e a uma sacralidade que referendava o poder divino ou soberano, agora podemos dizer que a morte se tornou, em alguns casos, o signo do fracasso de um poder que vacila em manter a vida a salvo de riscos e de condições degradantes de sobrevivência. Talvez seja essa a questão social que esteja presente nos assassinatos dos moradores de rua em Maceió. Do mesmo modo, estas mortes que ganham repercussão através das mídias são inseridas numa rotina de práticas e de discursos que visam questionar as formas contemporâneas de proteção da vida. Portanto, é a própria vida que é colocada em jogo na cena da morte dos outros.

É a vida pregressa dos sujeitos assassinados nas ruas que é tomada como parâmetro para indicar uma causalidade, os riscos e as vulnerabilidades produtores destas mortes no âmbito social. Também é sobre as vidas dos (sobre)viventes que as medidas e as ações políticas irão intervir para evitar que voltem a acontecer com a mesma frequência.
Ora, agora o poder é cada vez menos o direito de fazer morrer e cada vez mais o direito de intervir para fazer viver, e na maneira de viver, e no "como" da vida, a partir do momento em que, portanto, o poder intervém sobretudo nesse nível para aumentar a vida, para controlar seus acidentes, suas eventualidades, suas deficiências, daí por diante a morte, como termo da vida, é evidentemente o termo, o limite, a extremidade do poder. Ela está do lado de fora, em relação ao poder: é o que cai fora de seu domínio, e sobre o que o poder só terá domínio de modo geral, global, estatístico. Isso sobre o que o poder tem domínio não é a morte, é a mortalidade. (Foucault, 1999, p. 295-296).

Foucault (1999) ressalta que, com a mudança do poder soberano para o biopoder a morte é ressignificada, tornando-se algo que deve ser escondido, pois é algo vergonhoso. Segundo o filósofo, a racionalidade do poder soberano dava à morte um significado de passagem de um poder soberano terreno para outro poder soberano do além. Do mesmo modo, esta questão da morte é um ponto importante para pensar a gênese do poder em Foucault, pois ao afirmar que "o poder já não conhece a morte" (Foucault, 1999, p. 296), está-se afirmando o caráter criativo e produtivo do poder. Nestes termos, a morte é o limite inevitável ao poder, uma vez que com ela a vida - elemento originário do poder (Agamben, 2010) - cessa. Como algo inevitável, a morte faz escapar 
ao poder, no entanto, é por meio dos domínios biopolíticos que se produz um poder não sobre a morte, mas sobre a mortalidade, como um elemento a ser governado no corte biopolítico que separa os sujeitos em coletividades nas populações.

Portanto, vida e morte tornam-se elementos de governo através de um corte biopolítico nas populações humanas: a partir da natalidade e da mortalidade, como domínios estatísticos, o poder produz vida e morte passíveis de governo, num regime de utilidade para o desempenho das funções sociais. Por isto, Foucault (2008) afirma que o biopoder vai se ocupar da vida para aumentá-la, para maximizá-la como um bem útil, destinando-a ao melhor que se pode extrair dela.

Assim, ao se fazer da morte um evento midiático de interesse social, o que está em jogo é a própria vida da população. Nestas coberturas midiáticas, o espetáculo de imagens - que a mídia seleciona ao produzir informação em diversas etapas da produção de notícias -compõe uma realidade sobre a qual os sujeitos são chamados a atribuir sentidos, compondo uma história coletiva e particular destes eventos, colocando-se em jogo na cena coproduzida pelos meios de comunicação.

Nestes eventos, é o valor da vida que é posto em destaque. A morte torna-se um espetáculo na medida em que produz uma cena em que os sujeitos são forjados e a forjam conjuntamente. Portanto, é atuando sobre a virtualidade dos comportamentos individuais, tendo o indivíduo como elemento a partir do qual o governo das condutas se torna possível, que o espetáculo irá se efetivar como um importante instrumento biopolítico. Nestes termos, “o espetáculo pode ser considerado uma forma de exercício de poder biopolítico; e a biopolítica, um instrumento do espetáculo do capitalismo, para a construção de uma sociedade segura" (Fahri Neto, 2007, p. 21).

Podemos considerar, então, que, na contemporaneidade, vida e morte não são elementos puramente naturais, mas resultados de uma racionalidade de poder produzidos no cálculo biopolítico. São produtos de relações de poder, inseridos numa rotina de práticas e saberes tomados, de modo geral, nos domínios estatísticos que criam um ambiente sobre o qual é possível manipular variáveis para o governo das virtualidades em uma população.

O espetáculo midiático, por sua vez, cria condições para gerir a vida, considerada como algo natural, ao mostrar uma situação de morte como inevitável, com simultaneidade e realismo evidentes: na espetacularização de um evento que culmina com a morte de alguém há uma materialidade dos fatos que ganha força de verdade, naturalizando-a. 


\section{Onde há vida, há poder}

Em suas obras, Foucault (1988, p. 104-105) assinala que o poder é produtivo e "que lá onde há poder há resistência". Então, ao apoiar e ter na vida seu caráter estratégico, o poder a investe em seus cálculos, no sentido de um rearranjo das relações de força para a construção de estratégias de governo das populações. É, portanto, a partir da resistência nas relações de poder que as estratégias de governo da vida são forjadas. A vida e a sua proteção tornou-se fundamental ao poder. Como afirma Pelbart (2011, p. 13), "a defesa da vida tornou-se um lugar-comum. [...], a vida mesma tornou-se um capital, senão 'o’ capital por excelência, de que todos, e qualquer um, dispõem, virtualmente, com consequências políticas a determinar".

É neste cenário biopolítico que os assassinatos de moradores de rua são tomados como uma questão social que põe em xeque este poder, pois como conceber que um poder que visa à produção de condições plenas à vida, produza também o assassínio de sujeitos ao relegá-los a condições inóspitas de sobrevivência e por último a condições de morte e extermínio? Ora, Foucault (1999) afirma que

Temos de produzir a verdade como, afinal de contas, temos de produzir riquezas, e temos de produzir a verdade para produzir riquezas. E, de outro lado, somos igualmente submetidos à verdade, no sentido de que a verdade é a norma; é o discurso verdadeiro, que, ao menos em parte, decide; ele veicula, ele próprio propulsa efeitos de poder. Afinal de contas, somos julgados, condenados, classificados, obrigados a tarefas, destinados a uma certa maneira de viver ou a uma certa maneira de morrer, em função de discursos verdadeiros, que trazem consigo efeitos específicos de poder. (Foucault, 1999, p. 29)

A produção de verdades em inquéritos policiais e a veiculação destas verdades nas mídias são, portanto, formas de exercício de poder que decidem, classificam, condenam e destinam de modo naturalizado, para certos sujeitos, formas de viver e de morrer. Este poder, que questiona a si mesmo e a nós na busca de uma verdade originária sobre o que somos e desejamos, irá se encontrar diante não da morte, mas dos seus efeitos de poder nos dados estatísticos, dos cálculos e registros efetivados pelos domínios de saber contemporâneos.

É através da mortalidade produzida nos cálculos biopolíticos das mortes em uma determinada população que o poder irá se questionar e produzir outra economia de forças, que não seja a do extermínio anunciado para estes sujeitos. A morte, como limite ao poder e fragilidade da vida, irá aparecer como um desafio às tecnologias biopolíticas, na medida em que este poder 
é posto em dúvida como defensor da vida e de seu pleno desenvolvimento.

Agamben (2008), ao se referir ao extermínio de judeus no campo de concentração de Auschwitz, afirma que a morte "é a simples possibilidade da impossibilidade de todo comportamento e de toda existência"; por outro lado, no campo a morte torna-se impossível: "o ser da morte está interditado e os homens não morrem, mas são produzidos como cadáveres" (Agamben, 2008, p. 81). O conceito de campo para este autor é fundamental para pensar a biopolítica contemporânea.

Para Agamben (2008), o campo de Auschwitz configura-se como um lugar no qual a morte se torna rotina, tanto quanto a produção de cadáveres. Afirma ainda que o campo é o espaço biopolítico no qual se opera um vazio jurídico capaz de naturalizar a morte de alguns sujeitos, produzindo-a como pura manifestação de violência que se coloca fora do direito, no entanto, não se situa numa exterioridade ao direito, mas o constitui em sua interioridade.

Quando uma vida não se normaliza segundo a forma como o direito impõe, poderá ser catalogada como vida perigosa. Nesse caso, sofrerá uma suspensão do direito que irremediavelmente a colocará numa forma de exceção e, consequentemente, em algum tipo de campo. (Ruiz, 2012, p. 14).
Ruiz (2012), numa (re)leitura do texto de Agamben, irá propor a senzala como “a primeira experiência jurídico-política de campo", assim "as vidas ali confinadas encontram-se capturadas num fora do direito. Nela, o único direito que existe é o da vontade soberana do feitor" (p. 17). Nestas premissas o campo irá se configurar como um espaço em que "a exceção se tornou a regra, [e] a vida existe como mera vida natural" (Ruiz, 2012, p. 18).

A partir disso, é possível dizer que as ruas e o viver nelas, podem constituir estes espaços urbanos minimamente como lugares nos quais imperam uma incerteza quanto à continuidade da vida e um regime de exceção em que é exposta à violência soberana de qualquer um. Neste caso, os assassinatos de moradores de rua em Maceió efetivam-se ao constituir um campo biopolítico, no qual a vida desses sujeitos é transformada em “mais uma”, em um número que se somará às estatísticas de segurança pública, numa simples produção de cadáveres, tornando-se indiscernível a forma como morreram e a morte em si.

Nestes termos, podemos pensar que tais mortes e a forma como ocorreram, confundem-se com uma mera produção de cadáveres de sujeitos sem história e anônimos. São humanos sem cidadania, sujeitos que foram produzidos numa relação de exceção 
com um poder soberano que não cansou em mostrar sua força de morte.

Segundo dados do Relatório Consolidado sobre as mortes de moradores de rua na cidade de Maceió- $A L$, elaborado pelo Ministério Público do Estado, em 2010 e 2011 foram registrados 65 assassinatos de moradores de rua na capital do Estado, sendo que 37 deles tiveram o inquérito policial concluído e, destes, 19 foram concluídos sem autoria delitiva. Além disso, 23 inquéritos não foram concluídos e sobre 5 não constavam informações quanto à instauração de inquérito policial.

Conforme o relatório do Ministério Público do Estado, os moradores de rua assassinados em Maceió tinham envolvimento com drogas e outros delitos, e seus assassinatos foram efetuados visando acertos de conta, motivados por desentendimentos e apostas de jogo, no entanto, também destaca "que se tornou evidente a vulnerabilidade das vítimas pela questão social, na condição de morador de rua, principalmente pela crescente violência na capital alagoana" (Ministério Público Estadual, 2012, p. 79).

A partir destes elementos podemos considerar que há uma naturalização de que a condição de morar nas ruas seja uma questão social de vulnerabilidade e que as ruas produzem essa exposição à morte dos sujeitos que se arriscam a viver nelas. Neste contexto, as ruas de Maceió associaram-se ao risco, à morte e toda sorte de ilícitos.

\begin{abstract}
Em razão da não localização de familiares de 10 (dez) vítimas, bem como por não portarem documentos de identificação civil, sendo conhecidas apenas por apelidos, suas identidades ainda não foram descortinadas, não sendo esclarecidas as cautelas legais adotadas pela autoridade policial e pela perícia técnica, quando do sepultamento das vítimas, com o fim de coletar dados de prova, como fotografias e material para exame de DNA, posteriormente. (Ministério Público Estadual, 2012, p. 79).
\end{abstract}

A morte desses sujeitos que moram nas ruas produzem cadáveres em série, num anonimato considerável. Tais mortes são tomadas pela impossibilidade de reconstrução de uma história de vida dos sujeitos, restando apenas seus corpos, seus cadáveres, como prova da existência de uma vida infame.

Em matéria do site de notícias Tudo na Hora, publicada em 13 de julho de 2012 sobre o relatório do Ministério público, acima mencionado, os assassinatos de moradores de rua chegam ao número de 80 , entre 2010 e 2012, sendo 16 assassinatos registrados até aquela data em 2012. Destacam ainda a seguinte passagem do relatório:

O fato de algumas [vítimas] serem portadoras de doença mental, as quais após serem abandonadas a própria sorte pela família e pelo poder público, passam 
a morar na rua, oportunidade que praticam pequenos delitos, principalmente contra o patrimônio, para a própria sobrevivência ou para manutenção do vício de drogas, principalmente o crack, uma vez que se tornam alvo fácil dos traficantes de drogas. Dessa forma, não se torna apenas um problema de segurança pública, mas social e de saúde pública, que precisa ser considerado pelas autoridades competentes. (Ministério Público Estadual, 2012, p. 79, grifo dos autores).

No trecho acima a situação dos moradores de rua é deslocada de uma questão criminal ou de segurança pública para ser relacionada à outra, social e de saúde pública, implicando medidas diversas das criminais. A partir daí, aqueles assassinatos requerem um envolvimento das políticas públicas de saúde e social para uma proteção de suas vidas e para a retirada destes sujeitos das condições de vulnerabilidade associadas ao viver pelas ruas da cidade.

Os assassinatos produzidos nesse campo são capturados pelos registros, relatórios e documentos de segurança pública, tornando-se números que se configuram numa relação de exceção com suas vidas, através de um abandono. Vidas humanas, mas desprovidas de qualquer direito, escapam à cidadania de quem vive na polis.

Em notícia divulgada pelo site da Prefeitura de Maceió em 28 de fevereiro de 2011, os moradores de rua da capital ala- goana teriam facilitada a emissão de documentos, como a certidão de nascimento e a carteira de identidade, com a justificativa de que esta "é uma ação muito importante, pois sem o registro civil ou identidade, fica difícil para esse cidadão ter seus direitos assegurados"1. É a partir dessas ações que se pretende a efetivação da garantia de direitos em relação aos moradores de rua em Maceió.

As mortes produzidas como acontecimentos nas cidades podem ser relacionadas com a racionalidade biopolítica presente em nossa contemporaneidade e apontada por Foucault (2008): uma mudança de um dispositivo disciplinar para outro de segurança, marcada pela naturalização dos fenômenos sociais como indispensáveis à vida na cidade.

Com o aumento populacional nas cidades, surge uma preocupação quanto ao controle eficiente dos fluxos, da circulação das coisas e das pessoas pelas cidades: “em outras palavras, tratava-se de organizar a circulação, de eliminar o que era perigoso nela, de separar a boa circulação da má, (de) maximizar a boa circulação diminuindo a má” (Foucault, 2008, p. 24).

O dispositivo de segurança, mencionado por Foucault (2008), terá consequências e um funcionamento diferente do disciplinar, criando e atuando sobre um meio 
dado, naturalizado por índices estatísticos e por um cálculo de custos.

Ela vai trabalhar, é claro, com a disposição do espaço, com o escoamento das águas, com as ilhas, com o ar, etc. logo ela trabalha sobre algo dado. (Em segundo lugar,) não se trata, para ela, de reconstruir esse dado de tal modo que se atingisse um ponto de perfeição, como numa cidade disciplinar. Trata-se simplesmente de maximizar os elementos positivos, de poder circular da melhor maneira possível, e de minimizar, ao contrário, o que é risco e inconveniente, como o roubo, as doenças, sabendo perfeitamente que nunca serão suprimidos. (Foucault, 2008, p. 25-26).

Portanto, no dispositivo de segurança não está em jogo um cessar dos roubos, das doenças ou de assassinatos, mas de mantê-los numa frequência conveniente, de modo que sua ocorrência se torne insignificante. Trata-se de mantê-los na esfera individual, ao trabalhar com probabilidades, não com aquilo que o autor chama de um nível de perfeição que os anule por completo. Deste modo, as cidades produzirão acontecimentos que serão tratados como naturais. Foucault (2008) ressalta que é a partir daí que as cidades se tornam um espaço de produção biopolítica de um "meio natural" no qual o humano é produzido como espécie.
Mais adiante, este autor se referirá ao surgimento da economia política, do homo oeconomicus, a partir da qual os dispositivos de segurança funcionarão em uma lógica de laisser-passer, ou seja, um deixar andar das coisas, pois elas naturalmente se rearranjariam. Nestes termos, é preciso deixar morrer, adoecer, roubar, e assim por diante, para que possa se produzir uma realidade, associada ao risco, sobre a qual as tecnologias biopolíticas irão intervir ao nível da população, produzindo e reconduzindo a cidade em seus fluxos.

Neste contexto podemos afirmar que declarações como as que virão a seguir, veiculadas no site da Prefeitura de Maceió, são pensadas numa lógica que visa minimizar ou aliviar a situação dos moradores de rua, em certa naturalização de seus assassinatos e de suas condições, como algo que pode ser alterado, mas que permanecerá acontecendo em algum nível. Nas matérias veiculadas no site da Prefeitura, podemos mencionar e destacar, respectivamente os seguintes trechos e expressões nos quais se afirma que o "Semas [Secretaria Municipal de Assistência Social] discute plano para aliviar situação de moradores de rua" ${ }^{2}$, ou, sobre as ações do Projeto Acolher Cidadão, que o "projeto prevê atingir a pelo menos 120 famílias que esmolam na capital para, [...], encontrar uma forma de minimizar o 
problema"3, ou ainda quando o secretário da Semas afirma que "precisamos do apoio de todos [...] para tentar minimizar a situação de pobreza e mendicância, principalmente no período natalino, em que muitas pessoas chegam $[\ldots]$ para pedir esmolas em Maceió"4.

Pois bem, é esta racionalidade de governo que se torna presente na forma como as cidades serão administradas através das tecnologias biopolíticas, entre elas o que Foucault (2008) chama de dispositivo de segurança.

\section{Questão de polícia, não. Questão de} Estado, de políticas públicas

\begin{abstract}
Para o promotor, nem todos os moradores de rua mortos estavam envolvidos com crime. "São pessoas que foram esquecidas pela sociedade e pelo poder público. Claro que muitas das vítimas tinham envolvimento com drogas, e por isso praticava pequenos furtos. Mas a responsabilidade disso é a ausência de políticas públicas para essas pessoas", completou. ${ }^{5}$
\end{abstract}

A declaração acima aponta-nos a responsabilidade do "poder público" quanto aos assassinatos de moradores de rua em Maceió, devido à ausência de políticas públicas voltadas para esses sujeitos. Ao que podemos pensar, esta ausência teria produzido condições de vulnerabilidade importantes para estes sujeitos que vivem nas ruas da cidade, remetendo-os ao abandono, a partir do qual se tornam alvos das drogas e de práticas de delitos.

Neste sentido, as situações de vulnerabilidade e desigualdade social, produzidas no âmbito da economia capitalista, aparecem como importantes para o desenvolvimento de políticas públicas sociais que visam minimizá-las (Höfling, 2001; Cruz \& Schiefferdecker, 2011). Portanto, tais condições imprimem uma demanda por políticas públicas, constituindo um campo sobre o qual irão desempenhar função relevante sobre a vida destes sujeitos.

Neste contexto, representantes dos direitos humanos, militantes e profissionais irão afirmar a relevância das políticas públicas sociais para o enfrentamento da situação dos moradores de rua na cidade, ressaltando que "o morador de rua não é uma questão de polícia e sim uma questão de estado, de políticas públicas". É neste viés que as políticas públicas encontram palco para sua atuação, visando à garantia de direitos para esta população.

\section{Planos, ações e metas: um espaço de} reforma da vida dos outros

O Comitê Intersetorial de Acompanhamento e Monitoramento da Política Municipal para a População em Situação de Rua de Maceió foi instaurado em 18 de novembro de 2010 por decreto municipal, 
como uma forma de enfrentamento dos assassinatos de moradores de rua na cidade. O Comitê Intersetorial é formado por 11 membros titulares e 10 suplentes, com representantes de secretarias municipais, entidades da sociedade civil e dos moradores de rua. Este tem por funções: sugerir ações, projetos e programas para a população que vive nas ruas; acompanhar e monitorar a efetivação da política municipal para esse segmento social; propor medidas que assegurem a articulação intersetorial relacionadas às políticas públicas; e deliberar sobre a maneira como serão conduzidos os seus trabalhos.

Uma das importantes ações efetivadas pelo Comitê Intersetorial foi a elaboração do Plano Intersetorial e Inclusivo de Ações e Metas para a População em Situação de Rua para o biênio 2011-2012. Este plano fora entregue à Prefeitura de Maceió em 22 de junho de 2011, trazendo sete eixos temáticos com medidas estratégicas de inclusão social, cidadania e proteção para a população de rua da cidade. Os eixos e suas respectivas ações podem ser visualizados na Tabela 1 abaixo.

Tabela 1

\section{Eixos}

\section{temáticos}

\section{Ações}

\begin{tabular}{|c|c|}
\hline $\begin{array}{l}\text { I - Trabalho } \\
\text { e geração de } \\
\text { renda }\end{array}$ & $\begin{array}{l}\text { • Inserção em programas de qualificação profissional; } \\
\text { • Inserção no mercado de trabalho; } \\
\text { • Geração de renda. }\end{array}$ \\
\hline $\begin{array}{l}\text { II - Direito, } \\
\text { cidadania e } \\
\text { assistência } \\
\text { social }\end{array}$ & $\begin{array}{l}\text { • Emissão de documentos civis; } \\
\text { • Assistência jurídica; } \\
\text { • Inclusão em programas sociais; } \\
\text { • Estimulação da organização do movimento da População em Situação de Rua. }\end{array}$ \\
\hline III - Saúde & - Garantia do acesso aos serviços de saúde à População de Rua. \\
\hline $\begin{array}{l}\text { IV - Segurança } \\
\text { Alimentar }\end{array}$ & $\begin{array}{l}\text { - Garantia do acesso à alimentação à população de rua atendida pela rede } \\
\text { sócio-assistencial. }\end{array}$ \\
\hline $\begin{array}{l}\text { V - Educação, } \\
\text { esporte, lazer e } \\
\text { cultura }\end{array}$ & $\begin{array}{l}\text { - Construção de um projeto educacional voltado para a População de Rua; } \\
\text { • Desenvolvimento de atividades educacionais, esportivas, culturais e de } \\
\text { lazer nos espaços existentes. }\end{array}$ \\
\hline VI - Habitação & • Inserção em programas de habitação de interesse social. \\
\hline $\begin{array}{l}\text { VII - } \\
\text { Abordagem } \\
\text { social }\end{array}$ & $\begin{array}{l}\text { - Implementação dos serviços especializados em abordagem de rua; } \\
\text { • Construção do processo de inclusão social das famílias e indivíduos em } \\
\text { Situação de Rua. }\end{array}$ \\
\hline
\end{tabular}

Fonte: Elaborada com base em documento referente ao Plano Intersetorial e Inclusivo, cedido pela OAB/AL. 
$\mathrm{Na}$ Tabela 1 podemos ver descritos sete eixos temáticos para as ações descortinadas pelo Plano Intersetorial e Inclusivo. Estes eixos visam garantir direitos constitucionais às pessoas que vivem nas ruas, através de um investimento em aspectos relevantes de suas vidas, como por exemplo: o lazer, o trabalho, a saúde, a educação, a habitação, entre outros. Neste artigo, destacaremos dois aspectos: 1) ocupação do tempo e dos espaços urbanos; e 2) ações relacionadas à garantia de cidadania e direitos.

Sobre o primeiro aspecto podemos destacar as ações relacionadas à forma como estes sujeitos circulam pelos espaços urbanos, ao exercício dos seus direitos de cidadãos e à forma como os ocupam no que se refere ao lazer, cultura, trabalho e habitação.

Em relação a este aspecto, lembramos que uma das dificuldades levantadas pelos pesquisadores que realizaram o censo nacional da população de rua em 2009, é o fato destes sujeitos se movimentarem pela cidade de forma constante, não tendo um lugar fixo em que possam ser localizados, podem um dia estar em um lugar, e noutro já estar alhures.

A mobilidade dessa população, inclusive no período noturno, impõe que o levantamento das informações seja realizado no menor período de tempo possível, para minimizar a dupla contagem. Assim, a estimativa do tamanho das equipes de campo pautou-se na expectativa do MDS de que as entrevistas fossem realizadas em apenas uma noite em cada grande área de concentração de pessoas em situação de rua (Brasil, 2009, p. 20).

Neste sentido, ter um trabalho, passar pelos serviços de saúde, dormir no albergue, se alimentar em lugares de referência e ter uma casa favorecem algum controle sobre estes sujeitos no que se refere tanto às garantias de seus direitos, como também ao possibilitar um mapeamento dos seus fluxos pela cidade, construindo uma rotina e outra forma de se relacionar com as ruas. Trata-se de favorecer a construção da tutela de suas vidas através da crescente institucionalização de aspectos da vida biológica: sua alimentação, os lugares em que dormem, sua saúde, atividades esportivas, enfim, o corpo destes sujeitos se tornam alvo de práticas e ações que os tomam numa rotina institucionalizada. Esta forma de lidar com seus corpos produzem o que chamamos de processos de qualificação das vidas destes sujeitos, na medida em que é pela tentativa de fazê-los úteis e produtivos ao mercado de trabalho e a uma lógica de consumo civilizada/capitalista que suas vidas se tornariam cheias de qualidades.

Agamben (2010), conforme já indicado por M. Foucault, afirma um movimento importante na política contemporânea, em que a vida biológica entra em cena 
como um articulador de ações e práticas das estratégias biopolíticas de governo do outro. É neste sentido, a vida qualificada se opõe ao simples fato de viver.

A entrada do Estado nesse jogo de governo dos riscos a que a vida da população de moradores de rua está inserida se configura naquilo que Foucault chama de governamentalidade, ou seja, às maneiras de governar os outros, mas também no que diz respeito ao governo de si, às estratégias de resistência (Castro, 2009). A função do Estado seria instrumentalizar as maneiras de governar estes sujeitos através dos domínios de saber nos registros, relatórios e pesquisas que criam uma realidade sobre como vivem e como ocupam as cidades. É esta racionalidade que é operacionalizada através da governamentalidade exercida de um lado pelo Estado e de outro pelos sujeitos, através de suas estratégias de resistência. Deste modo, conforme o então Ministro do Desenvolvimento Social e Combate à Fome, Patrus Ananias, em um tipo de prefácio do documento Rua: aprendendo a contar, com o título de Cada homem e a humanidade inteira:

Ao aprender a contar, a gente coloca o problema diante dos nossos olhos. E nos responsabilizamos em oferecer respostas e construir soluções. O problema de cada homem e de cada mulher se apresenta como um problema nosso, um dano em nossa humanidade. Temos de chegar aos mais pobres entre os pobres justamente porque são os que mais precisam. E nos mandam sinais diários de suas vidas em constante perigo. Estamos aprendendo a ler esses sinais para mudar a realidade, recuperando a dignidade de cada um. Na rua, em casa em todos os lugares (Brasil, 2009).

Neste sentido, destacamos os seguintes pontos: a) a importância de intervir sobre as condições de vida dos pobres que vivem em perigo social constante; e, b) a necessidade de apreender a realidade de vida destes sujeitos para intervir e construir soluções que tentem recuperar a dignidade de suas vidas, pois não se trata de um problema somente para estes sujeitos, mas um dano para a nossa humanidade.

Portanto, as políticas públicas destinadas àqueles moradores de rua, funcionarão não só como um recurso para um "resgate da dignidade" destes sujeitos, mas também como um importante instrumento de mudança nas condições de sociabilidade, dispondo-os em um novo rearranjo urbano, inclusive no que diz respeito as suas relações com as drogas, com as ruas e com as instituições destinadas ao cuidado de suas vidas. Este cenário irá proporcionar a configuração de uma urbanização que não passa necessariamente por uma reforma da arquitetura física da cidade, mas por um investimento em ações que tomam as vidas destes 
sujeitos como potencial para as transformações das condições sociais.

Sobre o segundo aspecto relacionado às ações de garantia de cidadania e direitos, uma dificuldade apontada pelas matérias de jornais e pelas entidades de direitos humanos de Maceió diz respeito à ausência de documentos de identidade ou certidão de nascimento, para a efetivação de direitos de cidadania aos moradores de rua. Estes documentos são importantes para que qualquer cidadão possa utilizar os serviços públicos de saúde, educação e tantos outros, além de serem necessários para que estes sujeitos possam ser beneficiados com políticas de distribuição de renda e de habitação dos programas sociais. A partir disto, a emissão de documentos torna-se uma forma de imprimir a estes sujeitos uma identidade de cidadão de direitos com a qual podem ter acesso aos programas sociais e serviços públicos, além de poderem ingressar no mercado de trabalho e de geração de renda.

A cidadania é, portanto, um valor atribuído aos sujeitos na medida em que têm suas vidas transformadas, através de processos burocráticos institucionalizados, nos quais se efetiva uma qualificação das vidas destes sujeitos. A forma como as ações do Plano Intersetorial e Inclusivo dispõe de uma série de aspectos das vidas dos moradores de rua em Maceió, constitui uma população de rua e instaura práticas de qualificação de suas vidas. A partir daí, trata-se de inserir mudanças em suas vidas através de um governo de suas condutas e de um rearranjo destes sujeitos nos espaços urbanos, seja deslocando-os para centros de tratamento de dependência química ou para habitações populares dos programas sociais.

Foucault (2010), ao construir a análise histórica das prisões, irá afirmar que o poder nas sociedades modernas irá se especializar em processos de reparo, de transformação do homem, visando adaptá-lo ao convívio social, entre outras coisas habilitando-o ao trabalho, construindo um corpo útil e dócil. Nesta medida, as técnicas disciplinares e o biopoder irão passear de mãos dadas, construindo uma cena a partir da qual haverá incessantemente a produção do humano através de processos de individualização de um lado, e, de outro, práticas de regulamentação do corpo social. Processos e práticas que se complementam nas estratégias biopolíticas gerando, uma para a outra, domínios sobre os quais irão intervir.

Ao Estado cabe reorientar a vida nas cidades para que possam alcançar uma utilidade satisfatória, que venha trazer riquezas e bens para a nação. Esta lógica de governo se estabelecerá em uma razão de Estado na qual a vida será regulamentada (Foucault, 2008).

A disposição de aspectos das vidas dos moradores de rua em Maceió, bem 
como a constituição de uma população, organizará estratégias políticas específicas, justificada pelo fato destes sujeitos viverem em vulnerabilidade que precisa ser amenizada para que haja um "resgate da dignidade" destas pessoas.

Quando a questão de "resgate da dignidade" das condições de vida dos moradores de rua é tomada como uma das prerrogativas das ações do Plano Intersetorial e Inclusivo, o que se objetiva é retirar estes sujeitos de condições de vulnerabilidade que venham a expô-los à morte e ao assassínio. Neste sentido, poderíamos afirmar que vivem em situações indignas de sobrevida, ou seja, vivem uma vida considerada indigna de ser vivida, pois colocam-nos numa relação constante com a morte, e, portanto, ao minimizar ou aliviar essa situação estaríamos redirecionando-os de um destino fatalista, ao inseri-los em práticas de qualificação de suas vidas. Como afirma Ruiz (2012), trata-se de uma manifestação do poder soberano do Estado sobre a vida, ao assumir para si a autonomia dos sujeitos e tentar lhes assegurar o direito de viver uma vida digna de ser vivida.

\section{Considerações finais}

Como apontado, o poder propõe-se a organizar, esquadrinhar e regulamentar aspectos das vidas dos moradores de rua em
Maceió para devolver alguma dignidade, ou seja, "através de um investimento político, é possível não só julgá-las dignas e indignas, como também administrá-las" (Silva \& Hüning, 2013, p. 260). Vida e morte tornam-se questões não somente científicas, relacionadas a um corpo biológico, mas também elementos constituintes da política contemporânea (Agamben, 2010).

Assman, Pich, Gomes e Vaz (2007, p. 24-25) afirmam que a vida é um "espaço de resistência" e que a biopolítica pode ser considerada "como possibilidade de produção de novas formas de vida". Ao afirmarem isto, ressaltam que a vida tem um poder criativo potente, produzindo sempre um resto ingovernável nas relações de poder: nunca capturada em tudo, a vida guarda um elemento de resistência e de criação.

Pensando essas questões, podemos ressaltar que embora as práticas e ações de governo implicadas nas políticas públicas tentem alcançar a vida dos sujeitos a que se destinam, cercando-as de todas as formas, suas vidas poderão produzir-se em outros modos de estar no mundo. Assim, concordamos com Assman, Pich, Gomes e Vaz (2007) ao afirmarem que a vida tem um poder de criação de si mesma, fundamental às engrenagens do poder.

A naturalização de condições de vida precárias para alguns sujeitos, produz 
a indiferença em relação à violência cotidianamente vivida por determinados grupos populacionais, como ocorre com os moradores de rua em Maceió. No entanto, esta mesma racionalidade que produz não apenas o assassínio biológico, mas também de formas de vida, põe em questão o próprio poder que deveria proteger a vida, mantendo-a em segurança.

Neste contexto, aparecem os discursos-práticas dos Direitos Humanos que reforçam a ideia de tutela de suas vidas para que seja possível a garantia de direitos e a retirada desses sujeitos das péssimas condições em que vivem e, assim, alterar a probabilidade de seu ingresso na criminalidade. Trata-se de assegurar o controle e a tutela desses sujeitos para que, deste modo, não ingressem definitivamente nas temidas classes perigosas.

Ao trazermos para o campo do debate acadêmico a problematização dos homicídios de moradores de rua em Maceió, as narrativas produzidas pela mídia e relatórios sobre os mesmos, procuramos evidenciar a conexão desses discursos com a constituição de formas de vida (mais ou menos qualificadas) e sua gestão nos espaços urbanos contemporâneos. Esse exercício também possibilita o estranhamento e a recusa da naturalização do presente e a constituição de estratégias e ferramentas que efetivamente permitam um futuro diferente.

\section{Notas}

${ }^{1}$ Matéria na íntegra no seguinte link: $<\underline{\text { http://maceio.id5.com.br/noticias/index. }}$ asp?vCod $=13577 \&$ idioma $=p t>$.

${ }^{2}$ Título de matéria veiculada no site da Prefeitura de Maceió em 11 de outubro de 2010. Para ler na íntegra, acessar o link a seguir: <http://maceio.id5.com.br/noticias/ index.asp?vCod=12680\&idioma $=\mathrm{pt}>$.

3 Matéria veiculada ao site da Prefeitura de Maceió, com o título de Projeto Acolher Cidadão começa levantamento de mendigos, na data de 25 de julho de 2006. Para ler na íntegra acessar o seguinte link: $<\underline{\text { http://maceio.id5.com.br/noticias/index. }}$ asp? $\mathrm{vCod}=3536 \&$ idioma $=\mathrm{pt}>$.

${ }^{4}$ Ver a nota 1.

${ }^{5}$ Matéria publicada pelo Uol Notícias em 19 de novembro de 2010, com o título de Secretário descarta ação de grupos de extermínio e diz que mortes de moradores de rua em AL são "criminosos se matando". Matéria na íntegra no seguinte link: $<\underline{\mathrm{http}}: / /$ noticias.uol.com.br/cotidiano/2010/11/19/ secretario-descarta-acao-de-gruposde-exterminio-e-diz-que-mortes-demoradores-de-rua-em-al-sao-criminososse-matando.jhtm>.

6 Trecho de matéria veiculada pelo site Melhor Notícia em 25 de novembro de 2010, com o título de Defesa Social 
debate abordagem a moradores de rua, que pode ser encontrada na íntegra através do seguinte link: < $\underline{\text { http://Www. }}$ $\underline{\text { melhornoticia.com.br/index/?head=noticia. }}$ $\underline{\text { mht\&node }=\operatorname{mn} 31382>}$.

\section{Referências}

Agamben, Giorgio. (2008). O que resta de Auschwitz: o arquivo e a testemunha (Homo sacer III). São Paulo: Boitempo.

- (2010). Homo sacer: o poder soberano e a vida nua I. 2.ed. Belo Horizonte: Editora UFMG.

Assman, Selvino J.; Pich, Santiago; Gomes, Ivan M., \& Vaz, Alexandre F. (2007). Do poder sobre a vida e do poder da vida - lugares do corpo, biopolítica. Temas \& Matizes, Dossiê Biopolítica, n. 11.

Brasil. (2009). Ministério do Desenvolvimento Social e Combate à Fome. Rua: aprendendo a contar: Pesquisa Nacional sobre a População em Situação de Rua. Brasília, DF: MDS; Secretaria de avaliação e Gestão de Informação. Secretaria Nacional de Assistência Social.

Castro, Edgardo. (2009). Vocabulário de Foucault: um percurso pelos seus temas, conceitos e autores. Belo Horizonte: Autêntica Editora.

Cruz, Lilian R. da, \& Shiefferdecker, Márcio A. (2011). Práticas Psicológicas e Políticas Públicas de Assistência Social: algumas interrogações. Disponível em: $<$ http://online.unisc. br/acadnet/anais/index.php/jornada psicologia/article/view/10219/46>. Acesso em 20 de dez. de 2012.

Farhi Neto, Leon. (2007). Disciplina ou espetáculo? Uma resposta pela biopolítica. Revista Aulas, Dossiê Foucault, n. 3, dez. 2006/mar. 2007. ISSN 1981-1225.

Foucault, Michel. (1999). Em defesa da sociedade: curso no Collège de France (1975-1976). São Paulo: Martins Fontes.

- (2008). Segurança, território, população: curso dado no Collège de France (1977-1978). São Paulo: Martins Fontes.

. (2010). Vigiar e punir: nascimento da prisão. 38.ed. Petrópolis, RJ: Vozes.

Höfling, Eloisa de M. (2001). Estado e Políticas (Públicas) Sociais. Cadernos Cedes, ano XXI, n. 55. Ministério Público de Alagoas. (2012). Portaria PEJ No 057, de 12.01.2012. Relatório Consolidado sobre as 
mortes de moradores de rua na cidade de Maceió-AL. Diário Oficial do Estado, Maceió, AL, 13 de jul. de 2012. Anexo. Disponível em $\quad<$ http://www.imprensaoficial. al/diariooficial/wp-content/ uploads/2012/07/03mp8.pdf $>$. Acesso em 27 de jul. de 2012.

Ruiz, Castor M. M. B. (2012). A sacralidade da vida na exceção soberana, a testemunha e sua linguagem: (re) leituras biopolíticas da obra de Giorgio Agamben. Cadernos IHU, Revista da Universidade do Vale do Rio dos Sinos do Instituto Humanitas Unisinos, São Leopoldo, RS, ano 10, n. 39.

Silva, Wanderson V. N. da, \& Hüning, Simone M. (2013). Políticas públicas e o governo da vida e da morte nas ruas das cidades. Em Cruz, Lilian R. da; Rodrigues, Luciana; Guareschi, Neuza M. F. (Org). Interlocuções entre a Psicologia e a Política Nacional de Assistência Social. Santa Cruz do Sul, RS: EDUNISC.

Recebido em: 04/11/2013 - Aceito em: 05/12/2013 